\title{
Quantitative Reliability Evaluation of Silicon Carbide-Based Inverters for Multiphase Electric Drives for Electric Vehicles
}

Research paper

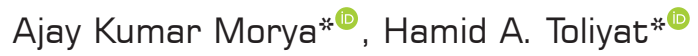 \\ Advanced Electric Machines and Power Electronics Lab, Texas A\&M University, College Station, TX, USA
}

Received: November 22, 2021; Accepted: January 29, 2022

\begin{abstract}
Reliability of power converter in the electric drivetrain of a vehicle can be a criterion for the comparison of various converter topologies, cooling system designs and control strategies. Therefore, reliability prediction is important for the design and control of vehicles. This paper presents an approach for quantitative evaluation of the reliability of converters for multiphase motor drives for electric vehicles (EVs) after considering the driving cycle. This paper provides a good background of reliability quantification so that it is easy to extend the presented approach to other applications. The models of subsystems have been selected to have excellent computational efficiency with good accuracy which is necessary for simulating long driving cycles. A simple vehicle model is used to obtain the traction motor torque demand for various points of the driving cycle. A multiphase interior permanent magnet synchronous motor has been used for traction motor. The operating voltage and currents of the motor are found using maximum torque per ampere (MTPA) control of IPMSM. The analytical loss calculation has been used to find the losses of switching devices of the converter. A thermal model of silicon carbide (SiC) MOSFET has been used to calculate junction temperature from the losses. The model developed here gives the failure rate and mean time between failures (MTBF) of switching devices of the inverter, which can be used to determine the failure rate. The model has been used to find the transition probabilities of a Markov model which can be used to quantify the reliability of converters of multiphase electric drives.
\end{abstract}

Keywords: electric vehicle • fault tolerance $\bullet$ Markov models $\bullet$ multiphase electric drive • reliability

\section{Introduction}

Electric vehicles (EVs) are gaining popularity as a result of increasing environmental awareness. Automotive companies are focussing on powertrain electrification as one of their core strategies to achieve mandatory government requirements on fuel efficiency around the world. However, power electronic systems in the drivetrain of a vehicle can have an adverse effect on the reliability of the vehicle (Masrur, 2008). For automotive applications, the typical design target of lifetime is 15 years with 10,000 operating hours and 300,000 km distance. The power electronics converters are usually the weakest links which limit the lifetime of the system. According to data obtained from field experience, approximately $35 \%$ of adjustable speed drive failures are attributed to the failure of power electronics (Garg et al., 2015). Up to $40 \%$ of three-phase inverter failures in the field are a result of power semiconductors failures. Wide bandgap devices are becoming state-of-the-art in power electronics. In Morya et al., 2019, a comprehensive review of applications of wide bandgap devices in motor drives is provided.

The reliability of the drivetrain of vehicles is an active area of research for both industry and academia. Reliability is the probability that a system will perform the required function without failure under the stated conditions for a specified period of time under given environmental and operational conditions. The probabilistic and deterministic approaches have been used in research on the reliability of power electronic converters and other components of electric drivetrain (Song and Wang, 2013). The inverter used in electric and hybrid electric vehicles (HEVs), wind energy conversion systems and photovoltaic power generation face randomly varying mission profiles (Ma et al., 2015; 
Hirschmann et al., 2007). Due to thermal variations, the bond wire and thermal joints of the switching device module can fail. Thermally caused failures constitute a significant percentage of all sources of failures (Wang et al., 2013). Quantitative assessment of reliability is important for comparing different topologies, control strategies and components and determining whether the designed system meets the specifications. Moreover, it can also be used for evaluating the effectiveness of various active thermal management strategies.

In Ciappa et al. (2013), a procedure to obtain the statistical distribution of thermal cycles experienced by power devices in HEVs operated according to a mission profile has been described. This enabled the design of accelerated tests tailored to realistic data and provides inputs for lifetime prediction models. In Song and Wang (2014), a missionprofile-dependent simulation model based on MATLAB has been presented for the quantitative assessment of the reliability of the three-phase motor drive of HEVs. In Song and Wang (2013), existing methods used to evaluate the reliability of power electronics converters are surveyed. In Bolvashenkov et al. (2016), the results of system analysis of different inverter topologies for traction drive of an electric helicopter have been presented. The Markov model of the multistate system has been used to study the reliability and fault-tolerance of the inverter.

The reliability of EVs can be enhanced by using multiphase motor drives having more than three phases. Other advantages of multiphase motors are smooth torque, lesser power rating per phase, reduced electromagnetic interference (EMI), etc. A machine with more than three phases can operate with the loss of one or more phases. It is important to quantify the reliability of multiphase motor drives to study the trade-off between reliability improvement and cost and complexity added due to the higher number of phases. There are some papers that discuss and try to quantify the reliability improvement with a multiphase motor drive. In Bolvashenkov et al. (2016), reliability and faulttolerance of multiphase traction motors based on Markov models for multistate systems have been discussed. In Olmi et al. (2015), a reliability assessment of a multiphase electric drive for underwater vehicle propulsion has been done. It investigates the reliability of three-phase, two three-phase and five-phase inverters. Markov model has been used to discuss the reliability improvement of the five-phase system compared to the other two systems. State transition diagrams have been employed to show reconfiguration capability in case of open-phase fault. There is no paper that quantifies the reliability of the inverter of a multiphase electric drive for EVs based on the mission profile.

In this paper, the procedure for reliability quantification of the inverter of a multiphase electric drive for EVs based on mission profile has been described. The selection of power module's rating also has an impact on the reliability of the power converter. Therefore, the model uses off-the-shelf SiC MOSFET modules of suitable rating and hence obtains practical values for reliability metric. Section 2 reviews the reliability analysis of power electronics systems including fault-tolerant systems. Section 3 describes different parts of the reliability quantification model. Section 4 evaluates the reliability using the Markov model.

\section{Reliability Analysis of Power Electronics System}

The first step in evaluating and improving system reliability is determining the reliability metric to analyse. The commonly used metrics for the evaluation of power electronics systems are reliability, failure rate, mean time between failures (MTBF), mean time to repair (MTTR) and availability. MTBF is a widely quoted performance metric for the comparison of various system designs (Song and Wang, 2013). MTBF gives the expected average time for which an item operates without failure. An MTBF much longer than the mission duration means that the system is highly reliable within the mission duration. MTBF is a basic measure of a system's reliability. Assuming that the failure rates of components and subsystems are independent of time, reliability can be defined as

$$
\text { Reliability }=e^{-t / M T B F} \text {. }
$$

The higher the MTBF, the higher the reliability. MTBF is typically represented in unit of hours. The failure rate is then estimated from the mean number of failures per unit time, which is expressed in failures in time (FIT)

$$
1 \text { FIT }=10^{-9} \text { failure / hour } \text {. }
$$

When the failure rate, $\lambda(t)$ is constant, the expression for MTBF is simplified to

$$
M T B F=\frac{1}{\lambda}
$$


Reliability analysis involves component-level or system-level models. For power electronics systems, reliability research at the component level is mainly focused on their failure rate models (Song and Wang, 2013; Hirschmann et al., 2007; Smatar and Dominguez-Garcia, 2010; Dominguez-Garcia and Krein, 2008; Petrone et al., 2008). Electrolytic capacitors and power switching devices are the most vulnerable components. This paper focuses on the failure rate of power devices.

Various reliability models are available for power devices. Empirical models are widely used to analyse the reliability of components. These models are based on observed failure data from field or laboratory tests. Military handbook for the reliability prediction of electronic equipment (Military-Handbook-217) (Reliability Prediction of Electronic Equipment, 1991) and IEC TR 62380 or RDF 2000 (IEC TR 62380, 2004) are the two well-known and widely accepted empirical-based reliability models. IEC TR 62380 considers the dormant modes and effects of the temperature cycles on failure rates and includes data of IGBTs. Since the empirical models of devices are based on observed data, reliability predictions are inaccurate for applications with different design, operational and environmental conditions. The Physics-of-failure method can model potential failure mechanisms (Bryant et al., 2008; Lambilly and Keser, 1993; Ciappa et al., 2003; Ma et al., 2016). The method considers electrical and mechanical stresses and temperature changes. However, building this model is complex and requires substantial knowledge about the physics and failure mechanisms of the device.

There is no empirical failure rate model available for $\mathrm{SiC}$ devices. As the objective of this paper is to present an approach for computing the quantitative reliability of multiphase electric drive topologies, the IGBT model of failure given in RDF 2000 has been used for simplicity. The SiC device datasheet parameters have been used.

\subsection{System-level reliability analysis}

For reliability analysis at a system- or sub-system-level, part count model, combinatorial model and Markov models are used. The system-level reliability model clearly depicts functional dependencies of components on each other and provides a framework for obtaining quantitative reliability. Part count model assumes the components of the system are connected in series and hence, the failure of a component will cause the system to fail. The failure rate of the system is the sum of the failure rate of components. The main advantage of this system is its simplicity and it is often adopted for power electronic converters. But, this model is not valid for systems that are fault-tolerant or which can be repaired. Combinatorial models are an extension to part-count models and include fault trees, success trees and reliability block diagrams. They can be used to analyse the reliability of simple redundant systems. Fault tree has been used to analyse the reliability of electric drives (Ying et al., 2009). Combinatorial models cannot reflect the details of fault-tolerant systems such as order of component failures, state-dependent failure rates, repair process and reconfiguration. Markov models can reflect all these details of fault-tolerant systems.

\section{Reliability Simulation Model of Electric Drive for Vehicles}

In this paper, a reliability simulation model is built to evaluate the reliability of SiC-based inverter for EVs. It takes into account various operating conditions of the vehicle. The block diagram of this simulation is shown in Figure 1. The MTBF and lifetime of the inverter and the whole system can be estimated from this model. Each block of the reliability simulation model has been described in the following sections.

\subsection{Driving cycle}

A driving cycle contains standard temporal sequence of vehicle speeds. The driving cycle provides instantaneous speed and acceleration to the vehicle and motor model. This is used to determine the operating conditions of the

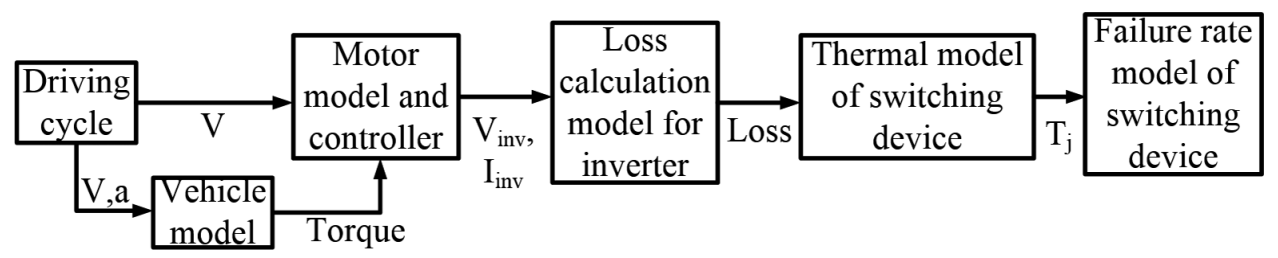

Fig. 1. Block diagram of the reliability simulation model. 
inverter in the electric drive. The required torque/speed versus time determines the operating conditions of the converter, which decide the electrical and thermal stresses of the components which are required for reliability estimation. The torque-speed profile of a vehicle also depends on vehicle parameters, road conditions and driver behaviour. Various driving cycles such as FTP-72, FTP-75, US06, NEDC, LA92 and Japanese 10-15 mode, are used in different countries to provide test benchmarks for evaluating fuel economy and emission of vehicles (Vehicle and Fuel Emissions Testing. Dynamometer Drive Schedules [Online]). These driving cycles have industry-wide acceptance and are used to emulate operating conditions for EVs. LA92 driving cycle (Vehicle and Fuel Emissions Testing. Dynamometer Drive Schedules [Online]) is used to simulate the driving scenarios in this paper, as shown in Figure 2.

\subsection{Vehicle model}

The vehicle speed and acceleration obtained from the driving cycle model are the inputs of the vehicle model to calculate the instantaneous torque and speed of the traction motor. Parameters of vehicle and road conditions such as gradient, road surface and wind speed combined with instantaneous torque-speed requirement determine the electrical operating conditions of the power electronics converter. The parameters of the vehicle, such as vehicle weight, front area and diameter of wheels, are obtained from the vehicle Toyota Prius. The rolling resistance coefficient, the aerodynamic drag coefficient and transmission efficiency are obtained from the literature (Ehsani et al., 2009). The vehicle parameters are shown in Table 1. Equations (4-9) are used to obtain required traction motor torque and speed with driving cycle data and vehicle dynamics as inputs and are stated as follows:

$$
\begin{aligned}
& a=\frac{V_{2}-V_{1}}{t_{2}-t_{1}}, \\
& \mathrm{~F}_{\mathrm{r}}=\frac{1}{4} * \mathrm{M} * \mathrm{~g} * \mathrm{f}_{\mathrm{r}},
\end{aligned}
$$

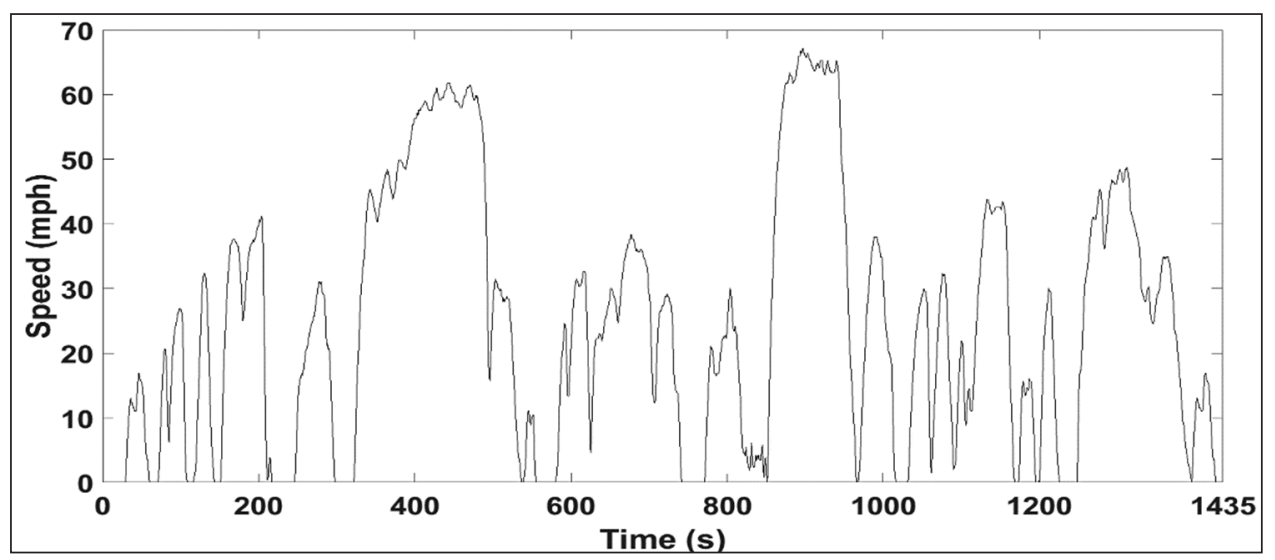

Fig. 2. LA 92 driving cycle.

Table 1. Parameters of vehicle

\begin{tabular}{ll}
\hline Parameter & Value \\
\hline \hline Front area & $1.746 \mathrm{~m}^{2}$ \\
Aerodynamic drag coefficient & 0.26 \\
Rolling resistance coefficient & 0.01 \\
Transmission efficiency & 0.9 \\
Vehicle mass & $1,243 \mathrm{~kg}$ \\
Radius of wheel & $0.3 \mathrm{~m}$ \\
\hline
\end{tabular}




$$
\begin{aligned}
& F_{w}=0.5 * \rho * A_{f} * C_{d} *\left(V-V_{w}\right)^{2}, \\
& F_{n e t}=F_{r}+F_{w}+0.25 * a * k * M \text { if } a>0, \\
& T_{m}=\frac{F_{n e t} * R_{w}}{n * G}, \\
& \omega_{m}=\frac{G * V}{R_{w}},
\end{aligned}
$$

where $a$ is acceleration. $V_{1}, V_{2}, t_{1}$ and $t_{2}$ are from the standard driving cycle LA92.

$F_{r}$ is rolling friction, $M$ is vehicle mass, $g$ is gravitational acceleration and $f_{r}$ is rolling resistance coefficient, $F_{w}$ is aerodynamic drag, $\rho$ is air density, $A_{f}$ is vehicle front area, $C_{d}$ is aerodynamic drag coefficient, $V$ is vehicle speed, $V_{w}$ is wind speed (assumed 0 in this paper).

$F_{\text {net }}$ is total traction effort needed. $k$ is a constant that is 1.0425 for passenger cars.

$\mathrm{Tm}$ is motor torque, $R w$ is radius of wheel, $n$ is transmission efficiency that is 0.9 and $G$ is gear ratio which is mentioned in Table 2. $\omega_{m}$ is motor angular speed.

\subsection{Motor model}

The Motor model, as described in (Jung et al., 2013), has been used to obtain stator voltages and currents using traction torque-speed obtained from the vehicle model. The EV motor parameters are taken from the literature (Jung et al., 2013) and are shown in Table 3. The motor can provide a maximum torque of $185 \mathrm{Nm}$, which was found to be sufficient for the considered vehicle and driving cycle. Exact sizing of the motor is out of the scope of this paper and does not affect the results reported here. The motor used is IPMSM, which is a superior solution for EVs because of its efficiency, power density and wide speed operating range. The reluctance torque can be utilised in the field weakening region. Therefore, the speed range of an IPMSM can be extended while maintaining a constant

Table 2. Gear ratio based on vehicle speed

\begin{tabular}{lc}
\hline Speed, $V($ miles $/ h)$ & Gear ratio \\
\hline \hline$\leq 8$ & 1 \\
$8<V \leq 24$ & 2 \\
$24<V \leq 48$ & 3 \\
$48<V \leq 64$ & 4 \\
$V>64$ & 5 \\
\hline
\end{tabular}

Table 3. Parameters of motor

\begin{tabular}{ll}
\hline Parameter & Value \\
\hline \hline Number of poles & 8 \\
Maximum speed & $10,000 \mathrm{rpm}$ \\
Maximum power & $70 \mathrm{~kW}$ \\
Maximum torque & $185 \mathrm{Nm}$ \\
Maximum current & $176.7 \mathrm{~A}(\mathrm{rms})$ \\
DC-link voltage & $360 \mathrm{~V}$ \\
Permanent magnet flux & $0.099 \mathrm{~Wb}$ \\
Nominal d-axis inductance & $0.312 \mathrm{mH}$ \\
Nominal q-axis inductance & $0.606 \mathrm{mH}$ \\
Stator resistance & $16.9 \mathrm{~m} \Omega$ \\
\hline
\end{tabular}


power. The high power density is due to its wide constant-power speed range. In IPMSM, torque is determined by both $d$-axis and $q$-axis currents. In the maximum torque per ampere (MTPA) method, the optimal combination of these two current components is calculated which produces the desired torque while minimising current magnitude. In the field-weakening region, current minimising solutions are found at the intersection of the torque and voltage limit curve. The analytical solution to current for MTPA has been obtained in (Jung et al., 2013) and the same has been used in our model.

\subsection{Post fault modelling and control of asymmetrical six-phase motor}

Multiphase motor drives have degrees of freedom that can be exploited during post fault to control the motor. The two most common optimisation criteria for post fault control are minimum-loss mode and maximum-torque mode. Note that we are using the maximum-torque mode, keeping the post fault currents below the rated value to satisfy the thermal limit of the power converter and motor. The detailed procedure to find the post fault currents has been described in Munim et al. (2017). A few other papers (Listwan and Pieńkowski, 2016; Listwan, 2018) discuss the control of multiphase motors well.

\subsection{Electro-thermal modelling and loss model}

Electro-thermal analysis of the system has become extremely crucial for reliability estimation. The device model, power loss model and thermal system model are an integral part of electro-thermal simulations (Zhang, 2007). These models are not compatible with each other in general as the simulation time-step required to solve them accurately is widely different. A fast method is required for predicting inverter performance and evaluation of switching devices. It is important to decouple the electric drive control simulation and thermal simulation to achieve faster real-time simulation, which is important for simulating vehicle standard driving cycles which last for several minutes. Thermal simulation is used to obtain device junction temperature. It is essential that all these models can be implemented in the same simulation environment or have convenient interfaces. The electro-thermal system should have high computational efficiency also to have fast simulation speed.

The stator voltages and currents obtained from the motor model determine the power losses in the converter. DC link voltage $360 \mathrm{~V}$ for the motor drive is considered here. A complete analytical solution to calculate the losses of switching devices of two-level voltage source inverter using phase currents and DC link voltage has been presented in Bierhoff and Fuchs (2004) and the same has been used by us. The best method to calculate power loss is by using mathematical model. In these models, the average values of current and voltage obtained from the control system of the power converter are used for loss calculation. This works very well for complex power converters like pulse width modulation controlled inverters. The loss model calculates conduction losses and switching losses using a simple model, which uses datasheet information. The linear loss model is assumed for the power semiconductor. The loss model used is a good choice for electro-thermal simulations as it has high computational efficiency.

\subsection{Thermal model}

The thermal model is used to calculate the junction temperature of the switching devices and detect thermal cycling. We use a partial fraction circuit for the thermal equivalent circuit of $\mathrm{SiC}$ module, which is also known as Foster model or pi model (Zhang, 2007; Thermal Equivalent Circuit Models. [Online]). This circuit is used in datasheets, as the coefficients can be easily extracted from a measured cooling curve of the power switch or module. The partial fraction coefficients are provided in the datasheet as thermal resistance $(r)$ and thermal time constant $(\tau)$ pairs with $\tau_{i=} r_{i} c_{i}$. The thermal time constant of SiC device package is of the order of hundreds of milliseconds. The thermal impedance curve can be written as:

$$
\begin{aligned}
& Z_{t h j c}(t)=\sum_{i=1}^{n} r_{i} *\left(1-e^{-t / \tau_{i}}\right), \\
& T_{j}(t)=P(t) * Z_{t h j c}(t)+T_{\text {case }}(t),
\end{aligned}
$$

where $P(t)$ is total loss, $T j(t)$ is junction temperature, $T_{\text {case }}$ is base plate temperature, $Z_{\text {thjc }}$ is junction to case thermal impedance, $r$ is thermal resistance, $T$ is thermal time constant and $T_{j}$ is junction temperature. 
In Ma et al. (2015), a loss and thermal model is presented that takes into account the electrical loading as well as devices rating as input variables. Both the electrical loading and device rating are important factors that determine the loss and thermal behaviours of power semiconductor devices. Considering this, the devices of the inverter have been selected to exactly match the loading requirement and the actual device datasheet parameters have been used.

The US department of energy has set certain goals and technical targets for the electric traction system of advanced vehicles (US Department of Energy (DOE), 2015). Thermal models developed at the national renewable energy laboratory show that using copper as the fin material with air flow through the micro-channels configuration and base plate held at $125^{\circ} \mathrm{C}$, heat fluxes from $60 \mathrm{~W} / \mathrm{cm}^{2}$ to $180 \mathrm{~W} / \mathrm{cm}^{2}$ can be dissipated. With aluminium as the fin material, the range was 50-150 W/ $\mathrm{cm}^{2}$ (Kelly et al.,2007). Keeping these future cooling technologies in mind, the baseplate or heat sink temperature is kept constant at $125^{\circ} \mathrm{C}$. Therefore, we do not need to simulate the cooling system using computational fluid dynamics (CFD) for finding the junction temperature and hence significant computation burden is avoided and simple thermal circuits have been used. In Drofenik and Kolar (2003), a method to calculate the junction temperature of the power module over a mains period with high accuracy by combining simple thermal equivalent circuits and stationary thermal simulations of the cooling system has been described. CFD software ICEPAK was used to generate transient and steady-state thermal simulations of liquid cooling of the power module.

\subsection{Failure rate model}

The failure rate model is used to calculate the reliability of power devices using electrical and thermal stresses obtained from the loss model. The failure mechanisms of power electronics are complicated and are affected by many factors. Thermal cycling that occurs due to temperature swings inside or outside the components, is one of the most critical failure causes in power electronics systems. The variable mission profile results in loading variations in power electronics components, which cause complicated thermal cycling. This paper uses the reliability handbook RDF 2000, which has empirical-based failure rate models. It covers dormant modes and the effects of the temperature cycles. The military handbook for the reliability prediction of electronic equipment (MIL217F) does not take into account the thermal cycling and dormant modes. Therefore, the component failure rate models provided by RDF 2000 are utilised to analyse the reliability of HEV powertrains. The failure rate models of power components are introduced as follows and the MOSFET failure rate model in IEC TR 62380 (2004) can be expressed as:

$$
\begin{aligned}
& \lambda_{\text {MOSFET }}=\left(\lambda_{\text {die }}+\lambda_{\text {package }}+\lambda_{\text {overstress }}\right) * 10^{-9} / h, \\
& \lambda_{\text {die }}=\pi_{S} * \lambda_{0} * \frac{\sum_{i=1}^{y}\left(\pi_{t}\right)_{i} * \tau_{i}}{\tau_{\text {on }}+\tau_{\text {off }}}, \\
& \lambda_{\text {package }}=\left(2.75 * 10^{-3} * \sum_{i=1}^{z}\left(\pi_{n}\right)_{i} *\left(\Delta T_{i}\right)^{0.68}\right) * \lambda_{b}, \\
& \lambda_{\text {overstress }}=\pi_{i} * \lambda_{\text {EOS }},
\end{aligned}
$$

where $\lambda_{\text {die }}$ represents the failure rate of MOSFET die, $\lambda_{\text {package }}$ represents the MOSFET package failure rate, which is caused by thermal cycling, $\lambda_{\text {overstress }}$ denotes the effect of overvoltage and overcurrent stress on the component failure rate, $\lambda_{o}$ and $\lambda_{b}$ are base failure rates of the die and the package, respectively, $\Pi_{s}$ denotes the effect of the voltage stresses and is determined by the ratios of the applied collector-to-emitter and gate-to emitter voltages to the corresponding rated voltages, $\left(\pi_{t}\right)_{i}$ represents the effect of junction temperature on the failure of the die in the ith phase of mission profile, $\tau_{i}$ is the working time ratio of the MOSFET in the ith phase of the mission profile, $\tau_{\text {on }}$ corresponds to the total working time ratio, $\tau_{\text {off }}$ corresponds to the total dormant time ratio, $\tau_{i}, \tau_{\text {on }}$ and $\tau_{\text {off }}$, representing the effect of the dormant mode on the failure of MOSFETs, $(\Delta T)_{i}$ is the amplitude of the thermal variation in the ith phase of the mission profile and $\left(\pi_{n}\right)_{i}$ is the factor that takes into account the annual number of thermal cycles seen by the package with the amplitude of $(\Delta T)_{i}$.

The unit of the failure rate in the given equation is the number of failures per billion $\left(10^{9}\right) \mathrm{h}$. 
Table 4. MOSFET datasheet parameters

\begin{tabular}{ll}
\hline Parameter & Value \\
\hline \hline Rated drain-source voltage, $V_{D S}(\mathrm{~V})$ & 1,200 \\
Continuous drain current, $I_{D}$ at $125^{\circ} \mathrm{C}$ case temperature $(\mathrm{A})$ & 95 \\
Maximum junction temperature $(\mathrm{C})\left(\mathrm{T}_{j, \text { max }}\right)$ & 150 \\
Turn-on switching energy $(\mathrm{mJ})$ & 1.7 \\
Turn-off switching energy $(\mathrm{mJ})$ & 0.4 \\
Diode forward voltage $(\mathrm{V})$ & 1.7 \\
On State resistance at $T j=150^{\circ} \mathrm{C}(\mathrm{m} \Omega)$ & 20 \\
Thermal resistance junction-to-case for MOSFET $\left(R_{\text {th } \mathrm{MCM}}\right)$ & 0.125 \\
Thermal resistance junction-to-case for diode $\left(R_{\text {th }, \mathrm{CD}}\right)$ & 0.108 \\
\hline
\end{tabular}

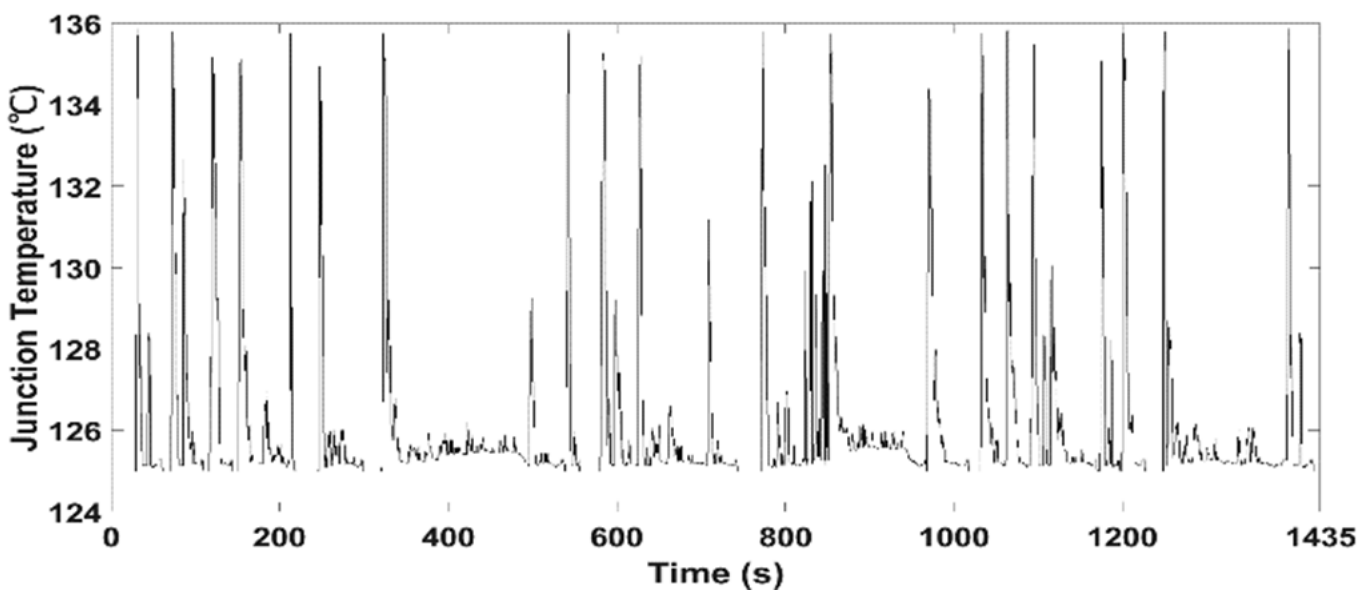

Fig. 3. The calculated junction temperature of SiC MOSFET for six-phase converter in LA 92 driving cycle.

\section{Reliability Evaluation and Discussion}

The average running time of a vehicle is $500 \mathrm{~h}$ per year IEC TR 62380 (2004). The thermal cycles of magnitude $3{ }^{\circ} \mathrm{C}$ are discarded as they have little effect on the failure rate. The air resources board LA92 driving cycle is used in this work. This is one of the most acceleration intensive standard driving cycles available, which makes it an obvious choice for studying the junction temperature variations with a high-efficiency SiC inverter. The device parameters have been taken from the datasheet of Cree SiC MOSFET CAS120M12BM2 and are given in Table 4. Figure 3 shows the junction temperature variation of devices of a six-phase converter supplying asymmetrical sixphase motor for LA 92 driving cycle as calculated using the model. The asymmetrical six-phase motor is described in Figure 4, the motor has two sets of three-phase windings with a 30-degree angle between them. A, B, C, X, Y and $Z$ are six phases of the motor. The switching frequency of the inverter was fixed at $10 \mathrm{kHz}$ and sine PWM was considered for conduction loss calculation. It can be observed in Figure 3 that the junction temperature of the device fluctuates a lot in a driving cycle.

The Markov model is based on graphical representation of system states that correspond to system configurations, which are reached after a unique sequence of failures and transition among these states. A sixphase motor drive can operate after loss of up to three phases. The Markov model diagram of a six-phase converter supplying asymmetrical six-phase motor is shown in Figure 5. S1 to S14 are states of motor drive and $\lambda_{x, y}$ represents the transition probability from state $x$ to state $y$.

Table 5 describes all the possible post-fault states of an asymmetrical six-phase motor drive used for generating the Markov model. There are 10 post-fault states in which the motor drive can operate with reduced performance. Based on the post-fault control strategy selected, the remaining phase currents will have different 


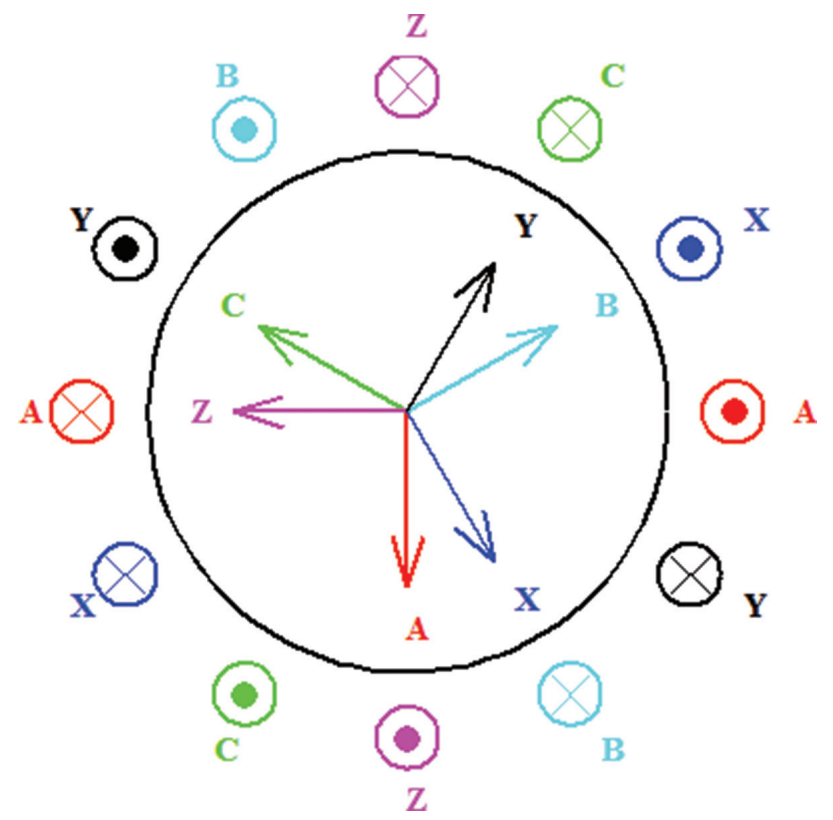

Fig. 4. Asymmetrical six-phase motor winding description with $A, B, C, X, Y$ and $Z$ denoting six phases of the motor.

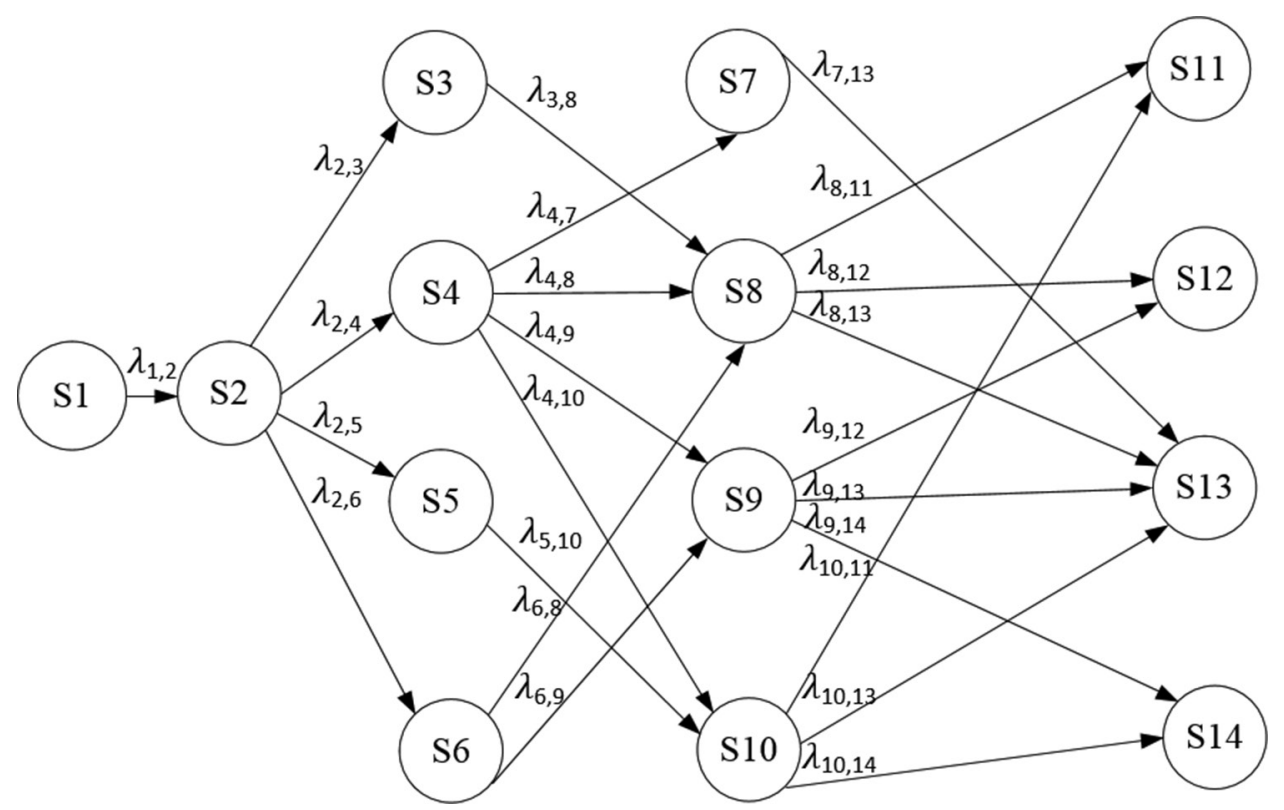

Fig. 5. The Markov model of a six-phase converter. S1-S14 are states of the motor drive. $\lambda_{x, y}$ represents the transition probability from state $x$ to state $y$.

magnitude and phase relationships among them and different junction temperature profiles in 10 post-fault states.

There are two types of states in Markov models: absorbing states that are associated with failed system configurations and non-absorbing states that correspond to configurations in which the system can function fully or partially. The model has 14 states represented by nodes: S1 to S14. S11, S12, S13 and S14 are absorbing states. The calculated transition failure rates are shown in Table 6 . Transition failure rates have been calculated using the method presented in this paper and the procedure is shown in Figure 6. The arrows represent the transition between states as a result of component failures. $\lambda_{x, y}$ represents the transition probability from state $x$ to state $y$. Evaluation 
Table 5. Post-fault states of motor drive for the Markov model

\begin{tabular}{lll}
\hline Motor drive state & Healthy phases & Status of healthy phases \\
\hline \hline 1 & All phases healthy & All phases healthy \\
2 & Five phases healthy & One of the phases faulty \\
3 & Four phases healthy & $30^{\circ}$ angle between faulty phases \\
4 & Four phases healthy & $120^{\circ}$ angle between faulty phases \\
5 & Four phases healthy & $150^{\circ}$ angle between faulty phases \\
6 & Four phases healthy & $90^{\circ}$ angle between faulty phases \\
7 & Three phases healthy & Three phases with $120^{\circ}$ angle among them healthy \\
8 & Three phases healthy & Three healthy phases with windings at $90^{\circ}$ and $120^{\circ}$ with first one \\
9 & Three phases healthy & Three healthy phases with windings at $120^{\circ}$ and $210^{\circ}$ with first one \\
10 & Three phases healthy & Three healthy phases with windings at $210^{\circ}$ and $240^{\circ}$ with first one \\
11 & Two phases healthy & $30^{\circ}$ angle between healthy phases \\
12 & Two phases healthy & $90^{\circ}$ angle between healthy phases \\
13 & Two phases healthy & $120^{\circ}$ angle between healthy phases \\
14 & Two phases healthy & $150^{\circ}$ angle between healthy phases \\
\hline
\end{tabular}

Table 6. Transition failure rate

\begin{tabular}{lc}
\hline Failure rate & Value $\left(/ 10^{6}\right.$ hours $)$ \\
\hline \hline State 1-2 $\left(\lambda_{1,2}\right)$ & 1.8000 \\
State 2-3 $\left(\lambda_{2,3}\right)$ & 0.2200 \\
State 2-4 $\left(\lambda_{2,4}\right)$ & 0.9370 \\
State 2-5 $\left(\lambda_{2,5}\right)$ & 0.2500 \\
State 2-6 $\left(\lambda_{2,6}\right)$ & 0.8388 \\
State 3-8 $\left(\lambda_{3,8}\right)$ & 0.2000 \\
State 4-7 $\left(\lambda_{4,7}\right)$ & 0.3200 \\
State 4-8 $\left(\lambda_{4,8}\right)$ & 0.2200 \\
State 4-9 $\left(\lambda_{4,9}\right)$ & 1.6914 \\
State 4-10 $\left(\lambda_{4,10}\right)$ & 1.6922 \\
State 5-10 $\left(\lambda_{5,10}\right)$ & 1.6916 \\
State 6-8 $\left(\lambda_{6,8}\right)$ & 1.6838 \\
State 6-9 $\left(\lambda_{6,9}\right)$ & 1.6838 \\
State 7-13 $\left(\lambda_{7,13}\right)$ & 2.2574 \\
State 8-11 $\left(\lambda_{8,11}\right)$ & 2.6304 \\
State 8-12 $\left(\lambda_{8,12}\right)$ & 0.2424 \\
State 8-13 $\left(\lambda_{8,13}\right)$ & 1.2000 \\
State 9-12 $\left(\lambda_{9,12}\right)$ & 0.5600 \\
State 9-13 $\left(\lambda_{9,13}\right)$ & 2.7946 \\
State 9-14 $\left(\lambda_{9,14}\right)$ & 3.2418 \\
State 10-11 $\left(\lambda_{10,11}\right)$ & 1.3002 \\
State 10-13 $\left(\lambda_{10,13}\right)$ & 10.9962 \\
State 10-14 $\left(\lambda_{10,14}\right)$ & 17.9298 \\
\hline
\end{tabular}

of the Markov model gives the probability of system being in one of the states. The Chapman-Kolmogorov equation is used to analyse the Markov model. For illustration, the Chapman-Kolmogorov equation for nodes S1 and S2 are given by: 


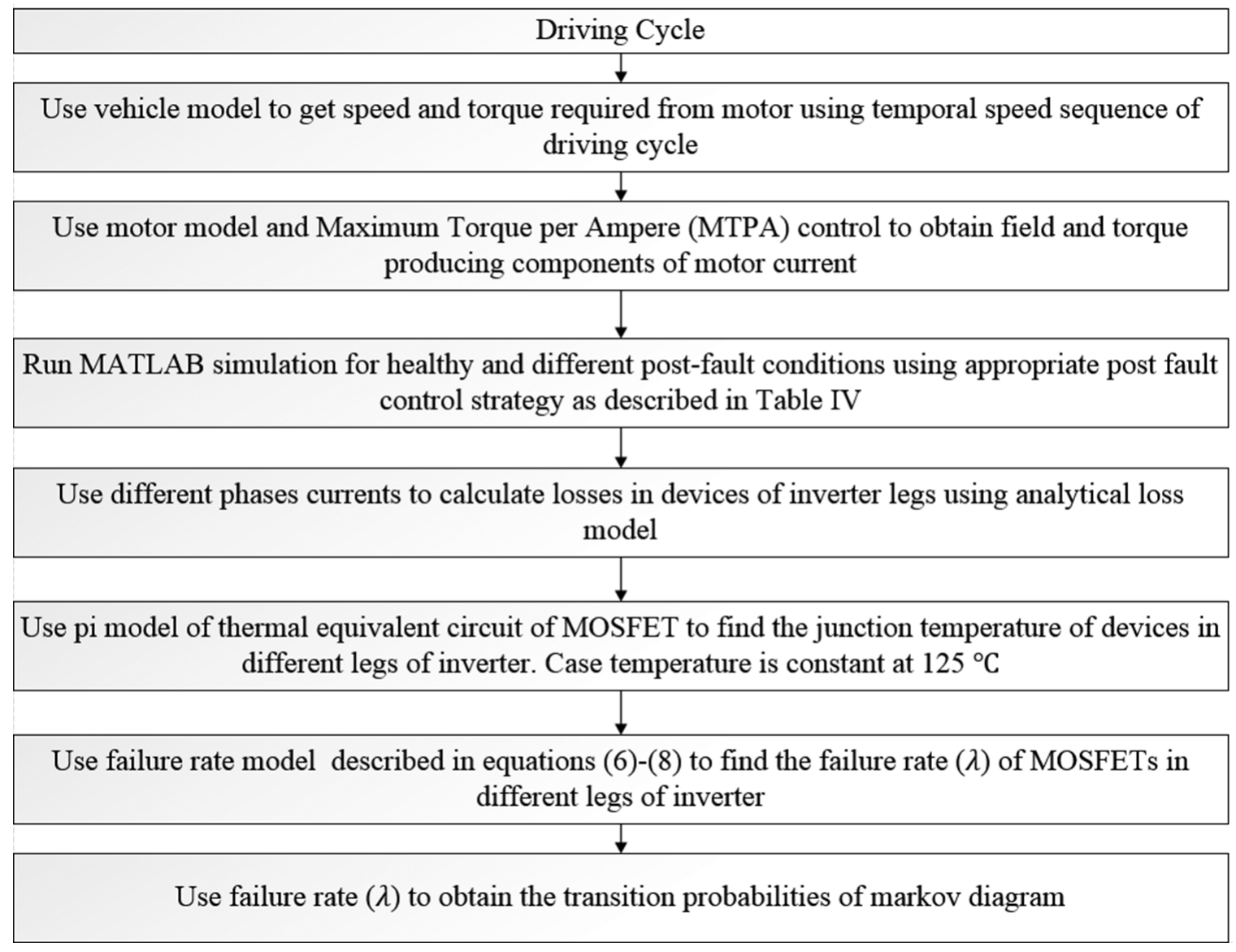

Fig. 6. Flow chart of the procedure for calculating the transition probabilities between different states of the six-phase motor. MTPA, maximum torque per ampere.

$$
\begin{aligned}
& \frac{d P_{S 1}(t)}{d t}=-\lambda_{1,2} P_{S 1}(t), \\
& \frac{d P_{S 2}(t)}{d t}=-\left(\lambda_{2,3}+\lambda_{2,4}+\lambda_{2,5}+\lambda_{2,6}\right) P_{S 2}(t)+\lambda_{12} P_{S 1}(t),
\end{aligned}
$$

where $P_{S k}(t)$ is the probability of a system being in state $k$ at time $t$. The system has 10 non-absorbing states: $S 1-S 10$. Therefore, at time $t$, the system reliability can be expressed as:

$$
R(t)=\sum_{k=1}^{10} P_{S k}(t) .
$$

For example, the probability of a system being in states $S 1$ and $S 8$ can be calculated using the following equations:

$$
\begin{aligned}
& P_{S 1}(t)=e^{-\lambda_{12} t}, \\
& P_{S 8}(t)=C_{X 8}\left(e^{-\left(\lambda_{38}+\lambda_{48}+\lambda_{68}\right) t}-e^{-\left(\lambda_{8,11}+\lambda_{8,12}+\lambda_{8,13}\right) t},\right. \\
& \text { where } C_{X 8}=\frac{\lambda_{38}+\lambda_{48}+\lambda_{68}}{\left(\lambda_{8,11}+\lambda_{8,12}+\lambda_{8,13}\right)-\left(\lambda_{38}+\lambda_{48}+\lambda_{68}\right)} .
\end{aligned}
$$




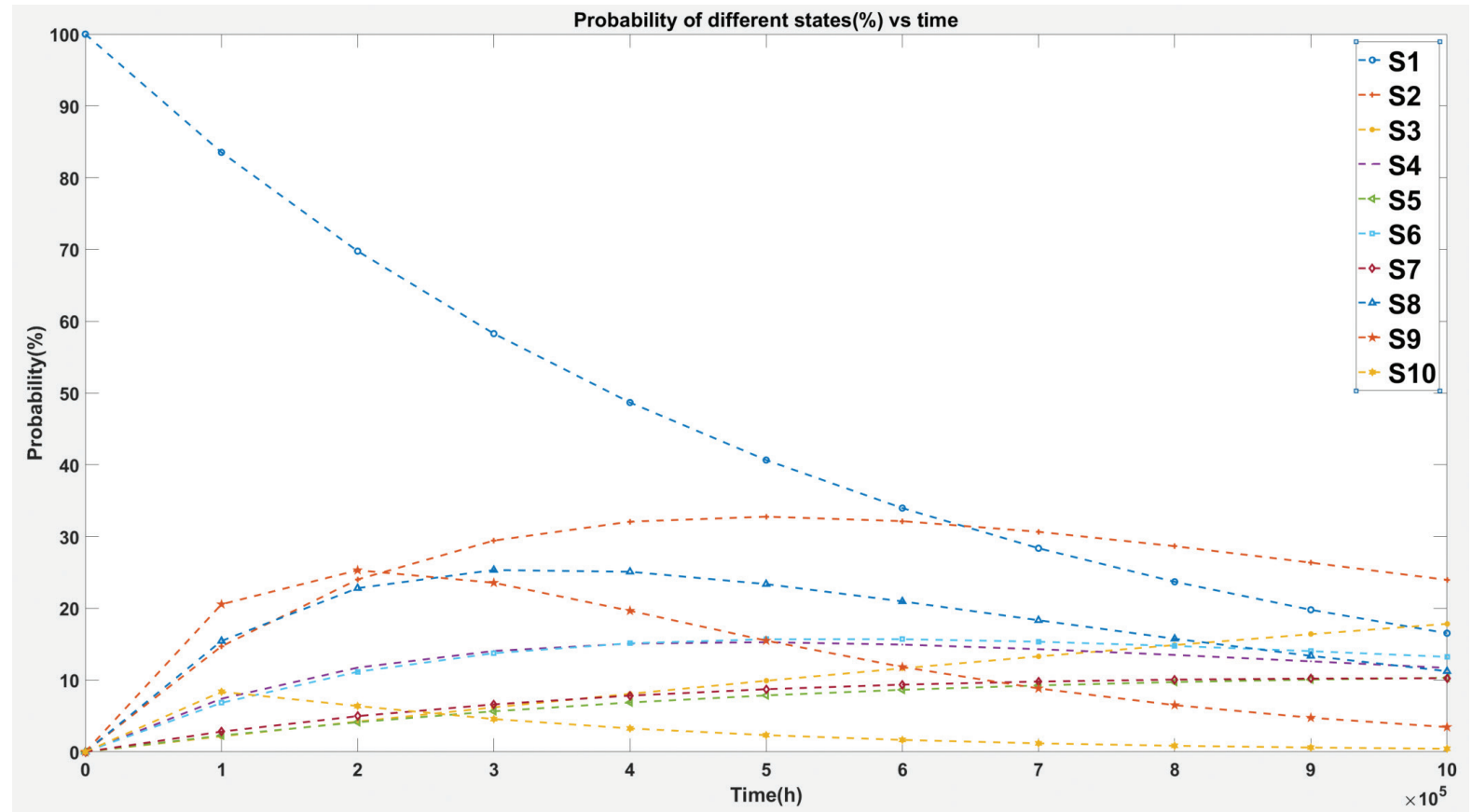

Fig. 7. Probability of different states of motor drive during the lifetime of a vehicle.

The probability of motor drive being in different states during the life of the vehicle has been calculated using the MATLAB-based model developed in this paper. The reliability of different motor states during the life of the vehicle is shown in Figure 7. The multiphase motor drive is able to operate with reduced performance in different states with loss of one or more phases and hence adds to the reliability of motor drive of the electric vehicle.

\section{Conclusion}

This paper presents a model based on the MATLAB model for quantitative reliability quantification of multiphase motor drives for EVs. The model is computationally efficient as it involves only equations that are solved quickly in MATLAB so that model can provide the output for tens of minutes long driving cycles quickly. The fault-tolerant operation is taken into account and the probability of motor drive being in different states vs time is obtained. This paper uses simplified models without compromising the accuracy for fast electro-thermal simulation of electric drives of EVs. A literature review has been provided to give a good idea of state-of-the-art to justify the choices made in modelling the different components. An asymmetrical six-phase motor drive has been used in the presented model. A Markov model showing transition probabilities and the overall failure rate has been presented. Quantitative reliability can be used as a criterion to select a multiphase motor drive for a particular traction application.

\section{References}

Kelly, K.J., Abraham, T., Bennion, K., Bharathan, D., Narumanchi S., O'Keef, M. (2007). Assessment of Thermal Control Technologies for Cooling Electric Vehicle Power Electronics. In: Proceedings of 2004 23rd International Electric Vehicle Symposium, Anaheim, California, USA [Online]. Available at: https://www.nrel.gov/transportation/assets/ pdfs/42267.pdf
Bierhoff, M. H. and Fuchs, F. W. (2004). Semiconductor Losses in Voltage Source and Current Source IGBT Converters Based on Analytical Derivation. In: Proceedings of 2004 IEEE 35th Annual Power Electronics Specialists Conference IEEE Cat, Aachen, Germany, pp. 2836-2842.

Bolvashenkov, I, Kammermann, J. and Herzog, H. G. (2016). Research on Reliability and Fault 
Tolerance of Multi-phase Traction Electric Motors Based on Markov Models for Multi-state Systems. In: Proceedings of International Symposium on Power Electronics, Electrical Drives, Automation and Motion SPEEDAM. Anacapri, pp. 1166-1171.

Bolvashenkov, I., Kammermann, J., Lahlou, T. and Herzog, H. G. (2016). Comparison and Choice of a Fault Tolerant Inverter Topology for the Traction Drive of an Electrical Helicopter. In: Proceedings of International Conference on Electrical Systems for Aircraft, Railway, Ship Propulsion and Road Vehicles \& International Transportation Electrification Conference. ESARS-ITEC, Toulouse, France, pp. 1-6.

Bryant, A. T., Mawby, P. A., Palmer, P. R., Santi, E. and Hudgins, J. L. (2008). Exploration of Power Device Reliability Using Compact Device Models and Fast Electrothermal Simulation. IEEE Transactions on Industrial Applications, 44(3), pp. 894-903.

Ciappa, M., Carbognani, F. and Fichtner, W. (2003). Lifetime Prediction and Design of Reliability Tests for High-power Devices in Automotive Applications. IEEE Transactions on Device and Materials Reliability, 3(4), pp. 191-196.

Ciappa, M., Carbognani, F. and Fichtner, W. (2013). Lifetime Prediction and Design of Reliability Tests for High-Power Devices in Automotive Applications. IEEE Transactions on Device and Materials Reliability, 3(4), pp. 191-196.

Dominguez-Garcia, A. D. and Krein, P. T. (2008). Integrating Reliability into the Design of FaultTolerant Power Electronics Systems. In: Proceedings of IEEE Power Electronics Specialists Conference, Rhodes, Greece, pp. 2665-2671.

Drofenik, U. and Kolar, J. W. (2003). Thermal Analysis of a Multi-chip Si/SiC-power Module for Realization of a Bridge Leg of a $10 \mathrm{~kW}$ Vienna Rectifier. In: Proceedings of International Conference on Telecommunications Energy (INTELEC '03). Yokohama, Japan, pp. 826-833.

Ehsani, M., Gao, Y. and Emadi, A. (2009). Modern Electric, Hybrid Electric, and Fuel Cell Vehicles: Fundamentals, Theory, and Design. 2nd ed. Boca Raton, FL, USA: CRC Press, ser. Power Electronics and Applications Series.

Garg, P., Essakiappan, S., Krishnamoorthy, H. S. and Enjeti, P. N. (2015). A Fault-Tolerant ThreePhase Adjustable Speed Drive Topology With Active Common-Mode Voltage Suppression. IEEE Transactions on Power Electronics, 30(5), pp. 2828-2839.
Hirschmann, D., Tissen, D., Schroder, S. and De Doncker, R. W. (2007). Reliability Prediction for Inverters in Hybrid Electrical Vehicles. IEEE Transactions on Power Electronics, 22(6), pp. 2511-2517.

IEC TR 62380. (2004). Reliability Data HandbookUniversal Model for Reliability Prediction of Electronics Components, PCBs and Equipment, First Edition. (Formerly RDF 2000 (UTE C 80810)).

Jahdi, S., Alatise, O., Fisher, C., Ran, L. and Mawby, P. (2014). An Evaluation of Silicon Carbide Unipolar Technologies for Electric Vehicle Drive-Trains. IEEE Journal of Emerging and Selected Topics in Power Electronics, 2(3), pp. 517-528.

Jung, S. Y., Hong, J. and Nam, K. (2013). Current Minimizing Torque Control of the IPMSM Using Ferrari's Method. IEEE Transactions on Power Electronics, 28(12), pp. 5603-5617.

Lambilly, H. D. and Keser, H. O. (1993). Failure Analysis of Power Modules: A Look at the Packaging and Reliability of Large IGBTs. IEEE Transactions on Components, Hybrids, and Manufacturing Technology, 16(4), pp. 412-417.

Levi, E. (2008). Multiphase Electric Machines for Variable-Speed Applications. IEEE Transactions on Industrial Electronics, 55(5), pp. 1893-1909.

Listwan, J. (2018). Application of Super-Twisting Sliding Mode Controllers in Direct Field-Oriented Control System of Six-Phase Induction Motor: Experimental Studies. Power Electronics and Drives, 3(38), pp. 23-34. doi: 10.2478/pead-2018-0013.

Listwan, J. A. and Pieńkowski, K. (2016). Direct FieldOriented Control of Six-Phase Indution Motor with Fuzzy-Logic Speed Controller. Power Electronics and Drives, 1(36), pp. 91-101. doi: 10.5277/ PED160107.

Ma, K., Bahman, A. S., Beczkowski, S. and Blaabjerg, F. (2015). Complete Loss and Thermal Model of Power Semiconductors Including Device Rating Information. IEEE Transactions on Power Electronics, 30(5), pp. 2556-2569.

Ma, K., Liserre, M., Blaabjerg, F. and Kerekes, T. (2015). Thermal Loading and Lifetime Estimation for Power Device Considering Mission Profiles in Wind Power Converter. IEEE Transactions on Power Electronics, 30(2), pp. 590-602.

Ma, K., Wang, H. and Blaabjerg, F. (2016). New Approaches to Reliability Assessment: Using Physics-of-Failure for Prediction and Design in Power Electronics Systems. IEEE Power Electronics Magazine, 3(4), pp. 28-41. 
Masrur, M. A. (2008). Penalty for Fuel Economy-System Level Perspectives on the Reliability of Hybrid Electric Vehicles During Normal and Graceful Degradation Operation. IEEE Systems Journal, 2(4), pp. 476-483.

Morya, A.K., Gardner,M.C., Anvari,B., Liu,L., Yepes,A.G., Doval-Gandoy,J., Toliyat,H.A. (2019) Wide Bandgap Devices in AC Electric Drives: Opportunities and Challenges. IEEE Transactions on Transportation Electrification, vol. 5, no. 1, pp. 3-20.

Munim, W. N., Duran, M. J., Che, H. S., Bermúdez, M., González-Prieto, I. and Abd Rahim, N. (2017). A Unified Analysis of the Fault Tolerance Capability in Six-Phase Induction Motor. IEEE Transactions on Power Electronics, 32(10), pp. 7824-7836.

Olmi, C., Scuiller, F. and Charpentier, J. F. (2015). Reliability Assessment of an Autonomous Underwater Vehicle Propulsion by Using Electrical Multi-phase Drive. In: Proceedings of Annual Conference of the IEEE Industrial Electronics Society, IECON, Yokohama, pp. 000965-000970.

Petrone, G., Spagnuolo, G., Teodorescu, R., Veerachary, M. and Vitelli, M. (2008). Reliability Issues in Photovoltaic Power Processing Systems. IEEE Transactions on Industrial Electronics, 55(7), pp. 2569-2580.

Reliability Prediction of Electronic Equipment (1991). Department of Defense, Washington DC, Tech. Rep. MIL-HDBK-217F, Dec. 1991.

Smater, S. S. and Dominguez-Garcia, A. D. (2010). A Unified Framework for Reliability Assessment of Wind Energy Conversion Systems. In: Proceedings of Power Energy Society. General Meeting, pp. 1-4.
Song, Y. and Wang, B. (2013). Survey on Reliability of Power Electronic Systems. IEEE Transactions on Power Electronics, 28(1), pp. 591-604.

Song, Y. and Wang, B. (2014). Evaluation Methodology and Control Strategies for Improving Reliability of HEV Power Electronic System. IEEE Transaction on Vehicular Technology, 63(8), pp. 3661-3676.

Thermal Equivalent Circuit Models. [Online] Available at: http://www.infineon.com/dgdl/ InfineonAN2008_03_Thermal_equivalent_circuit_ models-AN-v1.0 en.pdf?fileld $=\mathrm{db3a30431}$ a5c32f2 011aa65358394dd2

US Department of Energy (DOE). (2015). Office of Energy Efficiency and Renewable Energy (EERE), Electric Drives Technology, 2015 Annual Report [Online].

Vehicle and Fuel Emissions Testing. Dynamometer Drive Schedules [Online]. Available at: https:// www.epa.gov/vehicle-and-fuel-emissions-testing/ dynamometer-drive-schedules\#main-content

Wang, H., Liserre, M. and Blaabjerg, F. (2013). Toward Reliable Power Electronics: Challenges, Design Tools, and Opportunities. IEEE Transactions on Power Electronics Magazine, 7(2), pp. 17-26.

Ying, W., Jinsong, K., Ye, Z., Shiyi, J. and Dabing, H. (2009). Study of Reliability and Accelerated Life Test of Electric Drive System. In: Proceedings of IEEE International Power Electronics and Motion Control Conference, Wuhan, China, pp. 1060-1064.

Zhang, H. (2007). Electro-Thermal Modelling of SiC Power electronics Systems. PhD dissertation. Electrical Engineering Department, The University of Tennessee, Knoxville. 